healthcare-associated infections. Infect Control Hosp Epidemiol 2014;35:1083-1091.

2. Fortuna JA, Brenneman W, Storli S, Birnbaum D, Brown KL. The current state of validating the accuracy of clinical data reporting: lessons to be learned from quality and process improvement scientists. Infect Control Hosp Epidemiol 2013;34:611-614.

3. Birnbaum D, Fortuna JA. Washington State's experience applying ISO 2859 validation methods to healthcare associated infections (HAI) reporting. In: Program and abstracts of Council of State \& Territorial Epidemiologists Annual Conference; June 913, 2013; Pasadena, CA. Abstract 1386.

4. Lempp JM, Cummings MJ, Lovinger PG, Birnbaum DW. Cost of a sustainable annual validation process to ensure credibility of state HAI reporting. In: Program and abstracts of Council of State \& Territorial Epidemiologists Annual Conference; June 22-26, 2014; Nashville, TN. Abstract 135.

5. Healthcare Associated Infections Program Group Administrator Instructions for Validation of Surveillance Programs. Document available upon request to Washington State Health Department's Healthcare Associated Infections Program.

\section{Is It Necessary to Perform Hand Hygiene for Healthcare Workers Before Initial Patient Environment Contact?}

To the Editor-Hand hygiene is considered the simplest, most effective way to prevent healthcare-associated infections and stop the spread of pathogens. ${ }^{1}$ In recent years, more and more attention has been given to hand hygiene, and many guidelines already have been developed to improve hand hygiene practices in healthcare settings. ${ }^{2,3}$

According to the WHO Guideline on Hand Hygiene in Health Care 2009, the indications for hand hygiene were divided into 5 groups: (1) before touching a patient, (2) before a clean/aseptic procedure, (3) after body fluid exposure risk, (4) after touching a patient, and (5) after touching patient surroundings. ${ }^{4}$ It was especially noted that hand hygiene is not required before touching items in the patient zone but is required before direct contact with the patient. ${ }^{5}$

According to the Guideline for Hand Hygiene in Healthcare Settings, which was issued by the Healthcare Infection Control Practices Advisory Committee of the Hospital Infection Control Practices Advisory Committee/Society for Healthcare Epidemiology of America/Association for Practitioners in Infection Control/Infectious Diseases Society of America (HICPAC/SHEA/APIC/IDSA) Hand Hygiene Task Force in 2002 , the indications for hand rubbing with an alcohol-based hand rub or hand washing with soap and water were consistent with those of the World Health Organization (WHO).

Meanwhile, in Best Practices for Hand Hygiene in All Health Care Settings, ${ }^{6}$ which was developed by the Provincial Infectious Diseases Advisory Committee (PIDAC) of Canada, there are 4 moments when hand hygiene is performed: (1) before initial patient or patient environment contact, (2) before an aseptic or clean procedure, (3) after body fluid exposure risk, and (4) after patient or patient environment contact.

So, is it necessary for healthcare workers to perform hand hygiene before initial contact with the patient environment? These hand hygiene guidelines are significantly different.

During healthcare delivery, a patient's hands often directly touches the surfaces and substances in his or her immediate environment. With each patient-to-environment contact, a bidirectional exchange of microorganisms occurs between the patient and the touched items. ${ }^{1}$ Therefore, the patient and his/her immediate environment, also known as the patient zone, form an organic whole. This so-called patient zone includes some surfaces and items that are temporarily and exclusively dedicated to this patient. These surroundings include all inanimate surfaces that are contacted by or are in direct physical contact with the patient, such as the call button, remote control, bed rail, bedside table, bed linen, infusion tubing, and other medical equipment as well as personal items. Importantly, this zone contains surfaces frequently touched by healthcare workers while caring for the patient, such as knobs, equipment buttons, monitors, and other touchable surfaces. ${ }^{5}$

Healthcare workers' hands can become increasingly colonized by germs and potential pathogens during daily practice. ${ }^{78}$ If healthcare workers do not perform hand hygiene before touching patients, the germs and potential pathogens on their hands can be transmitted to the patients. When healthcare workers perform procedures without hand hygiene prior to entering a patient's surroundings, the surfaces and items the healthcare worker touches can be also be contaminated by germs and potential pathogens colonized on the healthcare worker's hands. These germs and potential pathogens can then be transmitted to the patients through the patient's contact with these surfaces and items. ${ }^{9}$ Potential pathogens on surfaces in the surrounding environment can be eliminated by cleaning and disinfection; ${ }^{10}$ however, those surfaces that are frequently touched by healthcare workers' hands may be quickly recontaminated.

In conclusion, healthcare workers should perform hand hygiene immediately before entering the patient zone, which includes both a patient and his or her surroundings.

\section{ACKNOWLEDGMENTS}

Financial support. This study was no funded.

Potential conflicts of interest. All authors report no conflicts of interest relevant to this article.

\section{Rong-hui Liu, MD, PhD; ${ }^{1}$ Duo-shuang Xie, MD, $\mathrm{PhD}^{2}$}

Affiliations: 1. Department of Infection Control, the First College of Clinical Medical Science, China Three Gorges University \& Yichang Central People's Hospital, Yichang, Hubei, China; 2. Department of Infection Control, Taihe Hospital, Hubei University of Medicine, Shiyan, Hubei, China 
Address correspondence to Duo-shuang Xie, MD, PhD, Department of Infection Control, Taihe Hospital, Hubei University of Medicine, No 32 Renmin Road, Shiyan, Hubei 430030, P.R. China (xieds8@163.com) Infect Control Hosp Epidemiol 2015;36(1):115-116

(C) 2015 by The Society for Healthcare Epidemiology of America. All rights reserved. 0899-823X/2015/3601-0020. DOI: 10.1017/ice.2014.31

\section{REFERENCES}

1. Pittet D, Allegranzi B, Sax H, et al. Evidence-based model for hand transmission during patient care and the role of improved practices. Lancet Infect Dis 2006;6:641-652.

2. Higgins A, Hannan MM. Improved hand hygiene technique and compliance in healthcare workers using gaming technology. J Hosp Infect 2013;84:32-37.

3. Scheithauer S, Oude-Aost J, Heimann K, et al. Hand hygiene in pediatric and neonatal intensive care unit patients: daily opportunities and indication- and profession-specific analyses of compliance. Am J Infect Control 2011;39:732-737.

4. Pittet D, Allegranzi B, Boyce J, for the World Health Organization World Alliance for Patient Safety First Global Patient Safety Challenge Core Group of Experts. The World Health Organization guidelines on hand hygiene in health care and their consensus recommendations. Infect Control Hosp Epidemiol 2009;30:611-622.

5. World Health Organization and WHO Patient Safety. Hand hygiene technical reference manual: to be used by health-care workers, trainers and observers of hand hygiene practices. Geneva: World Health Organization website. http://www.who.int/iris/handle/ 10665/44196. 2009. Accessed September 15, 2014.

6. Ontario. Provincial Infectious Diseases Advisory Committee. Best practices for hand hygiene in all health care settings. Ontario Ministry of Health and Long-Term Care website. http://www. health.gov.on.ca/english/providers/program/infectious/diseases/ic. hh.html. December 2010. Accessed September 15, 2014.

7. Sanderson PJ, Weissler S. Recovery of coliforms from the hands of nurses and patients: activities leading to contamination. J Hosp Infect 1992;21:85-93.

8. Landelle C, Verachten M, Legrand P, et al. Contamination of healthcare workers' hands with Clostridium difficile spores after caring for patients with C. difficile infection. Infect Control Hosp Epidemiol 2014;35:10-15.

9. Boyce JM. Environmental contamination makes an important contribution to hospital infection. J Hosp Infect 2007;65: $50-54$.

10. Weber DJ, Anderson D, Rutala WA. The role of the surface environment in healthcare-associated infections. Curr Opin Infect Dis 2013;26:338-344.

\section{The Carbapenemase Menace: Do Dual Mechanisms Code for More Resistance?}

To the Editor-Carbapenems (imipenem, meropenem, and doripenem) are used as the drugs of last resort to treat patients with resistant bacterial infections. These drugs possess a broad range of activity against numerous $\beta$-lactamases. The increasing

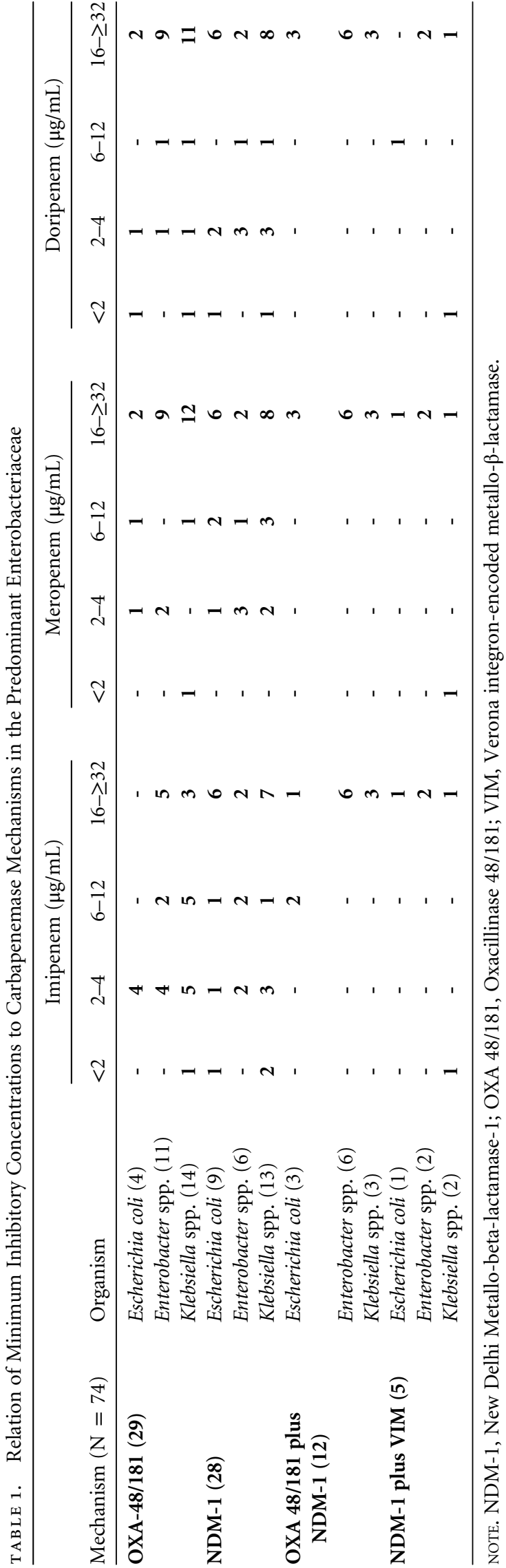

